\title{
POPULISMO E POLÍTICA 4.0: UM ESBOÇO ANALÍTICO
}

\author{
Estevão Rafael Fernandes
}

\section{Resumo}

O artigo buscará problematizar, a partir de alguns estudos de como o uso recente das redes sociais pelo presidente Jair Bolsonaro, em algumas situações recentes, nos abre espaço para repensarmos um populismo tech. Nosso objetivo é refletir sobre em que medida o uso de redes sociais em campanhas, na política, na comunicação institucional no Brasil contemporâneo, reforça e amplia práticas e papéis tradicionais, tanto na cultura política brasileira quanto nas redes de relações cotidianas para além da política.

Palavras-Chave: Populismo. Redes sociais. Comunicação Política. Twitter.

\section{Mídia e Política: O velho no novo?}

Em 2010 ministrei na Universidade Federal de Rondônia, uma disciplina intitulada "mídia, política e poder". O Whatsapp, aplicativo de mensagens mais popular hoje tinha apenas um ano, e mal era utilizado no Brasil. O Facebook, mesmo que largamente utilizado fora do Brasil, ainda não era tão difundido quanto hoje, em tempos nos quais o Orkut ainda era "a" rede social dos brasileiros. O Instagram ainda não tinha sequer sido lançado, e o Twitter disparava de 30 para 50 milhões de usuários - algo muito distante dos mais de 300 milhões de usuários daquela rede, atualmente. Naquele ano de Copa do Mundo ocorrida na África do Sul, nossas preocupações eram em torno de jabulanis e vuvuzelas e nem pensávamos no sete a um que viria, anos depois. Quase uma década parece uma eternidade, ao olharmos para trás.

Isso fica ainda mais claro ao olharmos com cuidado para algumas das referências utilizadas por mim naquele curso (BIROLI, 2009; BRAGA et al 2009; FINAMORE, CARVALHO, 2006; GOMES et al, 2009; LIMA et al, 1998): textos em sua maioria então recentes, discutindo temas como cobertura jornalística, fotografias e "Obama 2.0". Ao olhar, retrospectivamente, nada (repito: nada) nos prepararia para os tempos de hoje, com profusões de hashtags, memes, fake news e "pós-verdade". Mesmo textos como Castells (2013) sobre a utilização das redes em movimentos 
como a primavera árabe, ou as "jornadas de junho" de 2013, já parecem nascer ressequidos - ou alguém aí realmente se lembra dos 20 centavos, passado tão pouco tempo?

Mesmo quem se arrisca a entender essa sorte de fenômenos sabe que, a temporalidade necessária para filtrá-los sociologicamente às vezes não é suficiente para compreendê-los com o aprofundamento teórico, metodológico e político necessários. Não vou cair aqui nos lugares comuns de dizer vivermos em tempos líquidos, ou nos quais tudo o que é sólido se desmancha no ar. Minha intenção aqui, ao contrário, muito mais humilde, como se pode esperar de um ensaio, e vai no sentido de compreender como o uso dessas ferramentas, por mais que se nos imponham um outro ritmo em termos de compreensão, às vezes nos servem para desvelar mecanismos estruturais de poder.

Dito de outra forma: mesmo que a linguagem seja inovadora ou tech, a mensagem é nossa já velha conhecida e, daí, talvez, possamos ter uma análise politicamente mais situada e sociologicamente mais aprofundada. Em que medida 0 uso de redes sociais em campanhas, na política, na comunicação institucional, etc. no Brasil contemporâneo, reforça e amplia práticas e papéis tradicionais, tanto na cultura política brasileira quanto nas redes de relações cotidianas para além da política?

Em que pese a profundidade desses questionamentos, buscarei aqui trabalhar a partir de alguns estudos de caso - sabendo que, ao ser publicado em Somanlu, este texto talvez já soe datado. De qualquer forma, minha intenção aqui será tentar problematizar, nas próximas páginas, como o uso recente das redes sociais pelo presidente Jair Bolsonaro, em algumas situações recentes, nos abre espaço para repensarmos a separação - ou não - das esferas pública e privada na política nacional rumo a um populismo tech. Faço aqui uma ponderação importante: em que pese outros líderes mundiais fazerem amplo uso de suas redes sociais (como o presidente Donald Trump, por exemplo), Bolsonaro amplia seu uso para projetar uma imagem de homem do povo e pai de família. Minha hipótese é que uma das grandes inovações de Bolsonaro, no uso de sua comunicação pessoalinstitucional é, justamente, uma sobreposição permanente entre essas duas esferas - pública e doméstica. 


\section{Populismo 4.0? Algumas reflexões prévias}

Partamos aqui de uma hipótese prévia de trabalho: Bolsonaro é um líder populista. Não digo isso como forma de acusação, ou me posicionando pró ou contra o presidente, mas a partir da forma como mantém sua comunicação institucional e a partir de um conceito instrumental de populismo, dado por Tavares (2011) em seu excelente estudo sobre populismo na América Latina.

Nesse estudo, em que pese a polissemia ao qual o próprio o autor chama a atenção, o populismo hispano-americano (e penso que, mutatis mutandis, os populismos brasileiros) teriam como atributos

a) ênfase na soberania popular e uma concepção republicana, unitária, de povo; b) exercício do poder por um governante carismático e dotado de intenso respaldo pessoal junto aos cidadãos; c) ausência ou pouca influência de canais de mediação entre governante e governados; e d) modo de atuação que se concentra sobre o imediatismo, ou seja, sobre a rápida resposta e demonstração de resultados em relação às demandas apresentadas ao governo. [...]

A longo prazo, uma importante consequência do personalismo é o sacrifício da autonomia pública, ou seja, dos canais sociais e políticos que permitem aos cidadãos vocalizarem demandas positivas, controlarem o exercício do poder e, sobretudo, constituírem identidades políticas que possam ir além da afirmação de uma alteridade. O mesmo líder carismático que, em determinado momento, vocaliza demandas, estabiliza crises e enfrenta a dominação externa, se constitui, ato contínuo, como fator de represamento da auto-organização e expressão política dos cidadãos, ou seja, da manifestação de sua autonomia pública. (TAVARES, 2001, p. 49; 51).

Recuperando os pontos trazidos pelo autor, acima, indo ao encontro do que buscaremos desenvolver neste ensaio: governante com respaldo pessoal junto a seus governados; ausência de canais de mediação; imediatismo na demonstração de resultados... O que buscarei responder a seguir é: pode-se dizer que o presidente Jair Messias Bolsonaro seja, a partir dos atributos enumerados acima, "populista"? Minha hipótese é que seja, e que o seja justamente em suas práticas de comunicação pessoal-institucional por meio de seu uso do twitter.

Em tempo, uma observação importante: ao falar aqui em "pessoalinstitucional" busco demonstrar que ao compartilhar suas publicações nas redes sociais, não há uma separação clara entre a opinião pessoal de Jair e a posição 
institucional de Bolsonaro. Ainda que tal elemento não tenha sido de forma específica apontado por Tavares acima, penso que essa indistinção é a maior marca da administração bolsonarista até aqui e, exatamente aí, vemos essa miscibilidade entre o público e o privado - a qual, segundo indicado aqui, é a característica mais marcante da comunicação presidencial até aqui. Novamente: as duas esferas não se opõem nem se complementam, mas se confundem e imiscuem.

Em complemento ao que escreve Tavares na passagem acima, várias outras características são apontadas por analistas em política contemporânea como fundamentais para a compreensão do populismo ${ }^{15}$ : a ideia de que haja dois grupos distintos na sociedade: o povo e a elite corrupta; a ideia de representar "a vontade do povo" em oposição a "tudo o que está aí" (ou seja, o "sistema"); um modus operandi que os diferencie dos políticos "tradicionais", e a manutenção de um estado permanente de crise onde o líder assume um papel de protagonismo, acentuando seu papel de anti-establishment: ou seja: anti-elite, anti-intelecutalismo, anti-política. Como sintetizam Mudde e Kaltwasser (2017, p. 4), o populismo se caracteriza pela "concentração de poder e manutenção de uma conexão direta com as massas".

Retomando a questão acima - sobre populismo, Bolsonaro e twitter -; buscarei indicar alguns exemplos recentes a fim de serem recuperados adiante. Vale indicar que escrevo este texto em meados de março de 2019, e o perfil @jairbolsonaro naquela rede social conta com mais de três milhões e seiscentos mil seguidores. Parte razoável das publicações presidenciais dizem respeito a questões institucionais, tais como asfaltamento de rodovias, privatizações e reforma da previdência. Outras - que nos interessam aqui - trazem posicionamentos estritamente pessoais os quais quase sempre deixam claro uma sobreposição entre o ocupante do cargo (Jair) e o presidente (Bolsonaro) - impossível não me remeter a discussões tão caras na Antropologia nacional. Um parêntesis sobre isso: penso em Roberto Da Matta, especificamente) sobre temas como indivíduo e cidadão na sociedade brasileira enquanto relacional, e como instituições e relações pessoais são fundamentais na mediação entre sujeito e Estado, por exemplo. Entretanto, uma discussão que trabalhe de forma mais aprofundada esse tipo de relações em um contexto de populismo e mídias sociais denotaria um espaço, tempo e esforço que extrapolariam, e muito, os limites deste texto. Penso ser importante, dessa forma,

\footnotetext{
${ }^{15}$ A quem se interessar sobre o tema, recomenda-se a leitura de https://www.bbc.com/news/world-43301423, acesso em 13 de março de 2019.
} 
compreender que trabalho com Jair (indivíduo) e Bolsonaro (presidente) como tipos ideias não opostos, mas confluentes: um desprivatiza-se enquanto outro despubliciza-se, de forma mediada pelas mídias sociais. O simulacro resultante desse amálgama relacional é o que nos interessa, particularmente no tocante ao uso populista de "novas tecnologias" e mídias sociais.

O tom e temáticas das publicações em seu perfil deixam claro tanto a "ausência ou pouca influência de canais de mediação entre governante e governados" à qual Tavares chama a atenção na passagem citada acima, mas, sobretudo, como seus valores pessoais são tomados como "o" parâmetro para tomar decisões institucionais. A República é, aparentemente, uma forma de implementar o que Jair ("homem do povo", "gente como a gente") pensa e sente, havendo um gradual esvaziamento de mecanismos de controle social e institucional, culminando no "represamento" referido por Tavares na segunda parte de sua citação - como Mudde (2017) observa, populismo é o oposto de pluralismo, no qual tais controles operariam de modo mais efetivo. Chamo aqui a atenção ao que escreve Bobbio, no clássico Dicionário de Política, em seu verbete sobre República: "na República democrática a ordem política nasce de baixo, mesmo em meio de dissensões, desde que estas disponham de canais institucionais para se exprimir" (destaquei). Vejam bem: ao contrário do populismo, a República pressupõe por definição canais institucionais nos quais mesmo discordâncias possam ter espaço institucional.

Retornando ao @jairbolsonaro,o que temos?

\section{República Federativa... do Twitter?}

Pelo menos dois casos ocorridos nesses últimos meses chamam a atenção para como essas dissensões, usando aqui a expressão de Bobbio, são tratadas no âmbito institucional como forma de impor uma agenda pessoal sobre interesses institucionais.

O primeiro foram as críticas, ao atual presidente, pela indicação a um cargo dentro da Petrobrás de um suposto amigo pessoal do presidente para a gerência executiva de Inteligência e Segurança Corporativa da Petrobras, cuja remuneração giraria em torno de 50 mil reais por mês. Após a imprensa noticiar o caso, Bolsonaro tuitou em 11 de janeiro de 2019 "Peço desculpas à grande parte da imprensa por não estar indicando inimigos para postos em meu governo!". 
Meses depois, ao final de fevereiro de 2019, ao ser noticiada a nomeação da cientista política llona Szabó - especialista nacional e internacionalmente reconhecida no campo da segurança pública e política de drogas - para uma vaga de suplente no Conselho Nacional de Política Criminal e Penitenciária, a reação não veio diretamente do Presidente, mas de seus apoiadores online. A hashtag \#ilonanão chegou ao primeiro lugar nos trending topics mundiais com mais de 70 mil mensagens, resultando na desnomeação (sim, o verbo existe) da pesquisadora pelo Ministro da Justiça, Sérgio Moro - tendo sido comemorada por um dos filhos do presidente, Eduardo Bolsonaro:

Após exonaração de llana Szabó outro que era contra o projeto anti-crime de Moro pede para sair. O desarmamentista Renato Sérgio de Lima, do Conselho Nacional de Segurança Pública e Defesa Social, dispensou-se em solidariedade a Szabó \#grandedia (@BolsonaroSP) 28 de fevereiro de 2019.

Nos dois casos, temos algumas das características referidas acima, tais como o imediatismo e a troca de canais institucionais de comunicação por outros espaços sem mediação - e do discurso de "nós" versus "eles". Há, aí, uma clara supressão do pensamento dissonante, calcado na fórmula de que quem não pensa ou age em conformidade com o líder populista (e seus satélites) é inimigo da República, personificada no Presidente. De fato, um dos efeitos mais imediatos desse represamento comunicacional é, exatamente, a manutenção maniqueísta da existência de polos opostos. Esse tipo de retórica faz sentido em um contexto de campanha eleitoral mas, se mantida institucionalmente ao longo do governo, tem consequências sérias do ponto de vista do cerceamento de perspectivas diferentes inerente a regimes democráticos - como afirmamos, esse estado de crise atual é uma das características do populismo, e mantém a conexão entre o líder e seus seguidores.

Isso também fica claro no tipo de tratamento dispensado à imprensa ${ }^{16}$. Como apontou o Estado de São Paulo recentemente ${ }^{17}$, "a imprensa é alvo de Bolsonaro no twitter a cada três dias":

Em pouco mais de dois meses de governo, o presidente Jair Bolsonaro usou sua conta no Twitter para publicar ou

\footnotetext{
${ }^{16}$ Somaria a isso o episódio ocorrido em 10 de março envolvendo as críticas do presidente, em seu perfil, à jornalista do Estado de São Paulo, Constança Rezende, baseado em um áudio supostamente vazado por um suposto jornalista francês.

${ }^{17}$ https://politica.estadao.com.br/noticias/geral,imprensa-e-alvo-de-bolsonaro-no-twitter-a-cada-3dias,70002750823, acesso em 13 de março de 2019.
} 
compartilhar mensagens nas quais critica, questiona ou ironiza o trabalho da imprensa brasileira. Foram 29 publicações desde a posse até esta segunda-feira, 11, uma média de uma vez a cada quase três dias na rede social que o presidente tem utilizado como principal meio de comunicação com a população.

Nesse caminho, a partir de março, o presidente anunciou que faria vídeos ao vivo pela internet, como forma de "tratar de assuntos atuais" (7 de março), emendando, no dia 8: "Lamentavelmente parte da conhecida imprensa, sem o menor compromisso com a verdade, divulga informações distorcidas sobre uso do cartão corporativo. Mais uma irresponsabilidade desmentida durante nossa live de ontem". A transmissão veio um dia depois de duas postagens do suposto ideólogo do atual Governo, o astrólogo, digital influencer e auto-intitulado filósofo e cientista político Olavo de Carvalho (@opropriolavo), em 5 de março:

Os jornalistas brasileiros não o confessam, mas SABEM que ninguém liga para eles. A mais dolorida confirmação que tiveram foi a eleição do Bolsonaro, sendo essa a razão pela qual vão odiá-lo pelos séculos dos séculos.

Recomendo enfaticamente ao presidente da República: Fale diretamente ao povo num programa semanal em rede nacional de televisão. $E$ responda às perguntas do povo, não às de jornalistas.

Mais do que romper com a intermediação de canais institucionais (como porta-vozes) ou ao escrutínio da imprensa, não vejo essa estratégia de comunicação de Bolsonaro apenas como uma maneira de - relembrando as características trazidas por Tavares - falar diretamente ao povo sem mediadores, mas sim, de manter uma identificação direta com seu eleitorado, como "homem do povo". Exemplos disso são atitudes tomadas por ele como assinar seu termo de posse com uma caneta popular, posar para fotos junto com sua equipe de ministros com uma camisa falsificada de seu time (15 de fevereiro) ou ele haver almoçado em um bandejão de supermercado durante o fórum econômico em Davos, na Suíça (22 de janeiro). Além disso, vale a pena mencionar o caráter precário da live transmitida pelo presidente, tendo muito mais em comum com os vídeos que gravava durante as eleições do que com as possibilidades que um Presidente da República dispõe. Trata-se de manter uma continuidade narrativa entre a imagética construída ao longo da campanha com aquela, já após assumida a Presidência. 
Da mesma forma, há a narrativa de que no Brasil se trava uma "guerra cultural", como deixa claro em sua postagem do dia 5 de março: "Tão importante quanto a economia é o resgate de nossa cultura, que foi destruída após décadas de governos com viés socialista. Buscaremos o país da ordem e do progresso. Bom dia a todos!". Outros tuítes, mais recentes, também trazem essa retórica:

Não se refaz da noite para o dia algo tão grande, mas um ponto de partida já existe e estamos fazendo nossa difícil parte. Desejamos que outras gerações se organizem e levem adiante esta sementinha que foi plantada por muitos. e que impeçamos para sempre que o mal que esteve tão perto de destruir nosso país volte com força. Defeitos, todos temos, mas a maldade formada para destruir é nata e organizada apenas por um lado. Vamos trabalhar juntos para resgatar nosso amado Brasil! (@jairbolsonaro, 11 de março)

O ambiente acadêmico com o passar do tempo vem sendo massacrado pela ideologia de esquerda que divide para conquistar e enaltece o socialismo e tripudia o capitalismo. Neste contexto a formação dos cidadãos é esquecida e prioriza-se a conquista dos militantes políticos. (@jairbolsonaro, 11 de março)

A educação, aliás, é um campo privilegiado neste aspecto. Algumas postagens, por exemplo, em seu twitter no dia 4 de março deixam isso claro:

Brasil gasta mais em educação em relação ao PIB que a média de países desenvolvidos. Em 2003 o MEC gastava cerca de $\mathrm{R} \$ 30$ bi em Educação e em 2016, gastando 4 vezes mais, chegando a cerca de $R \$ 130$ bi, ocupa as últimas posições no Programa Internacional de Avaliação de Alunos (PISA)

Há algo de muito errado acontecendo: as prioridades a serem ensinadas e os recursos aplicados. Para investigar isso, 0 Ministério da Educação junto com o Ministério da Justiça, Polícia Federal, Advocacia e Controladoria Geral da União, criaram a Lava-Jato da Educação.

Dados iniciais revelam indícios muito fortes que a máquina está sendo usada para manutenção de algo que não interessa ao Brasil. Sabemos que isto pode acarretar greves e movimentos coordenados prejudicando o brasileiro. Em breve muito mais informações para o bem de nosso país. (@jairbolsonaro)

Educação, novamente - e esse é um tema para outro Artigo - tem sido, nesse sentido, uma das frentes com as quais a comunicação pessoal-institucional vem lidando, sistematicamente. Não me refiro aqui apenas às postagens e críticas (na live mencionada acima, inclusive) a materiais de educação sexual, à "ideologia de gênero" (sic), et caverna. Refiro-me ao que pode ser lido acima, nas entrelinhas: da 
educação superior como algo focado em "questões não prioritárias" e "algo que não interessa ao Brasil”. Exemplo disso vem na postagem do dia 28 de fevereiro:

Coréia do Sul lidera mundialmente o investimento em pesquisas e desenvolvimento de projetos (startups), enquanto que os mesmos setores no Brasil em simpósios de como fazer sexo anal sem sentir dor. Se depender de mim, a prioridade e seriedade terão outro direcionamento em breve.

Chamo aqui a atenção ao entrecruzamento semântico das duas postagens, deixando claro que, segundo se pode inferir, em princípio aquilo com o qual o posicionamento pessoal do Presidente não concorda torna-se, nos termos da postagem anteriormente referida, "algo que não interessa ao Brasil". O mesmo se tem, por exemplo, em live transmitida quando era ainda presidente eleito, no tocante ao Exame Nacional do Ensino Médio:

Esta prova do Enem - vão falar que eu estou implicando, pelo amor de Deus -, este tema da linguagem particular daquelas pessoas, o que temos a ver com isso, meu Deus do céu? Quando a gente vai ver a tradução daquelas palavras, um absurdo, um absurdo! Vai obrigar a molecada a se interessar por isso agora para o Enem do ano que vem?", indagou o presidente eleito.

Podem ter certeza e ficar tranquilos. Não vai ter questão desta forma ano que vem, porque nós vamos tomar conhecimento da prova antes. Não vai ter isso daí ${ }^{18}$

A título de registro, vale a pena registrar aqui as postagens de Bolsonaro sobre Golden shower após o carnaval deste ano (5 de março):

Não me sinto confortável em mostrar, mas temos que expor a verdade para a população ter conhecimento e sempre tomar suas prioridades. É isto que tem virado muitos blocos de rua no carnaval brasileiro. Comentem e tirem suas conclusões

Mais do que o polêmico vídeo que acompanhou a postagem (um performance em São Paulo em um bloco de carnaval), entendo que a postagem, em si, se insira em uma agenda muito mais ampla não apenas de "costumes" (como a pauta moral do Governo é conhecida, desde as eleições), mas em um contexto mais amplo: de manutenção da imagem de um líder carismático, do povo, com angústias e preocupações morais não apenas como Presidente, mas como pessoa. A primeira parte do texto acima - "temos que expor a verdade para a população ter conhecimento e tomar suas prioridades" - parece não fazer absolutamente nenhum

\footnotetext{
${ }^{18}$ https://g1.globo.com/politica/noticia/2018/11/og/bolsonaro-critica-questao-do-enem-2018-e-diz-que-em2019-vai-tomar-conhecimento-da-prova-antes.ghtml, acessado em 9 de março de 2019.
} 
sentido, se tomarmos os papeis estritamente institucionais esperados relacionados diretamente ao exercício da Presidência da República. Entretanto, é o papel esperado de um líder populista buscando reforçar, novamente: uma visão unitária de povo; respaldo moral; antagonismo diante do "politicamente correto" propagado pela "grande mídia" e "comunistas" (sic); e uma demonstração peremptória de choque/discordância que vai diretamente ao encontro de sua base eleitoral, conservadora nos costumes, constituindo e mantendo uma identidade política.

Nesse caso específico, vários eleitores de Bolsonaro com quem conversei disseram "mas o Jair é assim mesmo, ele não vai mudar só porque foi eleito" e é exatamente este o ponto: a manutenção da relação de uma identificação não apenas com o eleitorado, não a partir do Presidente Bolsonaro, mas do Jair, "gente como a gente". A questão - e espero deixar claro isso na última parte deste texto - é, justamente essa: o uso das redes sociais pelo Presidente nestes primeiros meses de mandato, bem como de pessoas próximas a ele vai no sentido de ampliar e manter essa relação do presidente como "homem do povo", simples, família, que usa roupa falsificada, caneta barata e come pão com leite condensado pela manhã, quando não está comendo em bandejões mundo afora.

\section{Algumas reflexões finais}

Muito pode ser escrito aqui para além do que escrevi - sobretudo a partir da polêmica demissão do então Secretário-Geral da Presidência, Gustavo Bebianno, em meados de fevereiro deste ano, após trocas de tuítes e vazamentos de áudios envolvendo o ex-Ministro, o Presidente e seu filho, Carlos Bolsonaro.

Como afirmei aqui, é difícil ao cientista social muitas vezes ter, em meio aos processos sociais que busca analisar, o distanciamento necessário para compreender de forma densa e profunda todas as complexidades envolvidas. Entretanto, penso que temos aí uma oportunidade única - e este texto é uma primeira tentativa nesta direção - de compreendermos mais profundamente a maneira pela qual o populismo é amplificado pelo uso de redes sociais. Talvez um estudo comparado com o contexto norte-americano nos trouxesse novas questões, ficando como sugestão a pesquisadores com interesse nessas temáticas. Da mesma maneira, temas como postagens feitas por bots em redes sociais, a profusão de 
notícias falsas e boatos pelo whatsapp (casos emblemáticos como a "mamadeira de piroca", por exemplo) seriam bem frutíferos, especialmente se cruzados com temas e conceitos clássicos no âmbito das Ciências Sociais, tais como poder, democracia e representatividade, por exemplo.

Não pude explorar aqui, infelizmente, as várias postagens de Bolsonaro referente a sua relação com sua família e com seus filhos. Digo isso pois acho importante apontar que parte da gestão das redes sociais do Presidente é feita por um de seus filhos - ou mesmo as polêmicas recentes entre os diferentes polos ligados à Presidência, sobretudo os militares e os olavistas.

No entanto, espero haver contribuído mesmo que preliminarmente para reflexões sobre a forma como o populismo pode ser compreendido no uso das redes sociais hoje, no âmbito da Presidência da República. Contudo, mais do que simplesmente aplicar um conceito ("populismo") ao uso de novas mídias, minha preocupação aqui é buscar indicar como (a) a sobreposição entre as esferas pública e doméstica; e (b) a amplificação do alcance das mídias, sobretudo pelo uso de novos aplicativos e de novas práticas impõe um aprofundamento desse conceito, em si. Sim, temos velhas práticas populistas operando, mas em um novo modelo de retórica e a uma velocidade assustadora. Quando comecei a escrever este texto afirmei que ele já nasceria velho mas me enganei: o que eu escrevi há alguns dias já foi superado e esse novo conceito de temporalidade e de espacialidade precisam ser encarados, também, ao se buscar compreender fenômenos tais como democracia, representatividade e poder. Mais do que comparar as práticas discursivas do atual presidente com outros contexto nacionais (como Trump, já mencionado aqui), talvez haja um campo vasto também caso tentemos compreendê-lo à luz das estratégias de propaganda da Ditadura militar no Brasil ou mesmo de outras figuras populistas (como Getúlio Vargas ao longo do Estado Novo - um estudo a partir do DIP parece algo interessantíssimo) ou com uma agenda de costumes semelhante ao atual ocupante do cargo máximo do Executivo (como Jânio Quadros, por exemplo). 


\section{Referências}

BIROLI, Flávia Disputas, ajustes e acomodações na produção da agenda eleitoral: a cobertura jornalística ao Programa Bolsa Família e as eleições de 2006. Trabalho apresentado no GT 11, no 33․ Encontro Anual da ANPOCS, 2009

BRAGA, Sérgio; BECHER, André; NICOLÁS, Maria Alejandra. Clientelismo, internet e voto: a campanha nos websites dos candidatos a vereador no Brasil Meridional. Trabalho apresentado no GT 11 da 33‥ Encontro anual da ANPOCS, 2009.

CASTELLS, Manuel. Redes de indignação e esperança: movimentos sociais na era da internet. Rio de Janeiro: Zahar, 2013.

FINAMORE, Cláudia Maria; CARVALHO, João Eduardo Coin de. Mulheres candidatas: relações entre gênero, mídia e discurso. Rev. Estud. Fem. vol.14, n.2, 2006.

GOMES, Wilson; FERNANDES, Breno; REIS, Lucas; SILVA, Tarcizio. Politics 2.0: A campanha online de Barack Obama em 2008. Sociol. Polit. Curitiba, v. 17, n. 34, out. 2009.

LIMA, Venício A. de; GUAZINA, Liziane, Política eleitoral na TV: um estudo comparado do Jornal Nacional (JN) e do Jornal da Record (JR) em 1998 (Relatório Preliminar). Trabalho apresentado no 22‥ Encontro anual da Anpocs, 1998.

MACHADO, M. A retórica da reeleição: mapeando os discursos dos Programas Eleitorais (HGPE) em 1998 e 2006. Opinião Pública, Campinas, Vol. 15, n. 01, junho, 2009.

MUDDE, Cas; KALTWASSER, Cristóbal Rovira. Populism: A very short introduction. Oxford University Press. 2017.

SORJ, Bernardo. Internet, espaço público e marketing político: entre a promoção da comunicação e o solipsismo moralista. Novos Estudos, 76, novembro de 2006.

TAVARES, Francisco Mata Machado. Três variantes do personalismo na política da américa hispânica: O caudilhismo, o bolivarianismo e o populismo como expressões de afirmação regional. Cadernos PROLAM/USP, 10(18), 38-52. DOI: https://doi.org/10.11606/issn.1676-6288.prolam.2011.82448. 2011 